\title{
HOBBES I EL MONARQUISME MODERN *
}

\author{
Norbert Bilbeny \\ (Universitat de Barcelona)
}

La incidència del pensament polític anglès en el marc de les cultures peninsulars ha estat certament exigua. Més particularment, pel que fa a la teoria política del filòsof anglès Thomas Hobbes (1588-1679), la transcendència de la qual en la moderna teoria de l'Estat és prou evident, cons. tatem, així mateix, el fet d'una ínfima repercussió en els sectors intellectuals hispànics.

Hem pogut detectar, però, la presència de Hobbes en l'obra del polític i publicista castellà Luis Araquistain (1886-1959), pertanyent al Partido Socialista Obrero Español (en representà la seva ala més esquetrana) i fundador del seu òtgan de premsa «Leviatán», de títol ben suggerent, del qual fou també director.' D'altra banda, observem la presència de Hobbes, en una data anterior, en els escrits del filòsof català Joan Crexells (18961926), qui l'any 1925 publicà l'article De Hobbes a Maurras a la «Revista de Catalunya». ${ }^{2}$ No hem pogut esbrinar la referència a Hobbes en l'àmbit

* Treball presentat en el seminari dedicat al pensament polític de Hobbes. Fa. cultat de Filosofia de la Universitat de Barcelona, abril de 1980.

1. La revista «Leviatán», publicada a Madrid entre 1934 i 1936, fou, com «Cla. ridad", una tribuna d'expressió teòrica del PSOE. Recordem que Leviathan (1651) és el títol de la principal obra de filosofia política de Hobbes, juntament amb les scves anteriors Elements of Law (1640) i De Cive (1642).

2. La «Revista de Catalunya», publicació literària i teònica mensual lligada al sector catalanista liberal, va ser donada a llum a Barcelona entre 1924 i 1931, és a dir, coincidint cronològicament amb ta dictadura militar. Quan Crexells hi publica el seu article n'era director Antoni Rowira i Virgili. 
hispànic més enllà d'aquests dos autors esmentats. Malgrat tot, la recepció de la teoria política hobbesiana se'ns presenta de forma ben diferent, àdhuc ideològicament oposada, entre ambdós autors. D'aquesta manera, el Hobbes entrat en el medi català és l'exaitador del monarca quasi absolut, el del Leviatan/monstre bíblic, mentre que l'introduït en el medi castellà repre. senta el Hobbes fundador de la teoria de l'Estat liberal, el del Leviatan/ representant del poble per la consumació del pacte civil. Aquesta doble interpretació del jlegat filosòfico-polític hobbesià (crítica, com es veutà, la de Crexells, i possiblement ingènua, ens atrevim a qualificar, si féssim una lectura seriosa de l'obra d'Araquistain) en el divers ambient cultural i polític hispànic dels anys vint del nostre segle es cotrespon amb la duplicitat mateixa que acompanya l'observació amatent de les tesis polítiques del pensador anglès: hi ha un Hobbes absolutista i un Hobbes liberal darrera del Leviathan. Hem optat per resseguir una d'aquestes lectures, $i$ ho ferm tot analitzant el text alludit de Joan Crexells, com a via d'accés al Hobbes del monarca absolut, un aspecte, aquest, poc investigat en l'exegesi hobbesiana. Altrament, la recerca sobre un Hobbes absolutista ens pot ajudar a tenir alguna referència conceptual més en l'estudi de la progressiva transformació de l'Estat liberal en el seu antagonista, és a dir, en un Estat on l'executiu és cada cop més reforçat. Ens limitarem, així, a determinar el valor de veritat de les afirmacions de Crexells per remissió a l'obra original de què tracta el seu article: el Leviathan.

\section{CREXELLS, CRITIC DE L'AUTOCRACIA}

El filòsof català Joan Crexells va escriure relativament poc, però amb densitat. Ell exa un home força polititzat, i el tema polític no és aliè a la seva obra. ${ }^{3}$ Un dels seus darrers escrits va ser l'article esmentat abans. ${ }^{4} \mathrm{El}$ text en qüestió consisteix en una defensa de la democràcia pluralista i parlamentària de la tradició liberal-burgesa, en contraposició al règim de govern dels sistemes autocràtics. Crexelis no ens diu, ni tampoc no deixa entreveure, quin és el model polític de democràcia que està pensant: no especifica, per exemple, els conceptes relatius a la sobirania, al règim de govern o a la forma d'Estat. Més que una filosofia política, expressa una filosofia estricta de la Democràcia, entesa com a forma d'existència social, no pas

3. Vid.: Norbert Bilbeny: Joan Crexells, en la filosofia del noucents. Barcelona, 1979 , pp. 125 i ss.

4. De Hobbes a Maurras, «Revista de Catalunya», 13, 1925, pp. 1-14. 
com allò que és políticament: una forma de poder. Allò que sí que deixa per ben entès l'article de Crexells és la concepció política que rebutia, en oposició a la que ell defensa. L'autor critica l'autocràcia, el règim de govern que concentra tot el poder en l'executiu.

Crexells ens posa davant del monarca com a figura que més representa el sistema autocràtic. Malgrat que no ens parla de les importants diferències entre el monarca absolut i el monarca constitucional, el corotiari del seu tefús de la dictadura se centra en la «Monarquia», sense més especificació. Però no és gens estrany. Els anys vint, mentre Crexells escrivia el seu article, registren no sols un acreixement de les forces socials antimonàrquiques a les velles monarquies europees (Regne Ünit, Bèlgica, Alemanya, Rússia, etc.), sinó, paradoxalment, un tessorgiment del monarquisme a les antigues repúbliques revolucionàries. És, aquest, el fenomen encapçalat per Mussolini, a Itàlia, i per Maurras, a França. Crexells veu així, en els moviments feixistes, un recobrament ideològic de la monarquia com la forma d'organització del poder que més convé als imperatius polítics del feixisme europeu de principis de segle. Tot el seu article, doncs, apunta contra aquest tipus de monarquisme, i per això escull com a blanc dels seus atacs el del seu contemporani francès Charles Maurras (1868-1952), fundador del corrent protofeixista L'Action Française ${ }^{5}$ i màxim defensor, en aquell temps, del retorn del monarca absolut. ${ }^{6} \mathrm{La}$ particularitat d'aquest article de Crexells, allò que li dóna entitat teòrica i xifra la qualitat de la seva aportació, és la tesi que el monarquisme modern coincideix amb el planteig del sobirà ideal que realitza Hobbes en el seu Leviatban. En una paraula, la teotització mautrasiana sobre la monarquia està continguda quasi explí. citament, per a Crexelis, en les definicions hobbesianes sobre el Sobirà de la Commonwealth. Vegem ara, altrament, $i$ en una breu síntesi, com el nostre autor ens presenta el monarquisme modern, del qual, més endavant del seu text, ens farà una crítica aferrissada.

El pensador català ens precisa, de bon antuvi, que el monarquisme es basa en la pretesa demostració que el dret a la igualtat entre els homes no

5. La influència de Maurras a Catalunya es patentitza a través d'Eugeni d'Ors i del corrent cultural noucentista que aquest animà. Com és sabut, Crexells i altres intellectuals catalans de la seva generació (Riba, Estelrich, Nicolau d'Olwer, etc.) es formaren a l'escalf de les institucions i publicacions educatives i culturals que d'Ors contribuí a crear a Catalunya $i$ en les quals ell mateix participà activament. L'influx maurrasià, compartit o no, exa, doncs, familiar entre aquells intellectuals.

6. Vid.: M. Mourre; Charles Maurras, Parîs, 1958; Z. Sternhell: La droite revolutionnaire (1885-1914). Les origines français du fascisme, París, 1972; així com els coneguts manuals d'història de les idees polítiques de $\mathrm{S}$. Giner: Historia del pensamiento social, Barcelona, 1975, i J. Touchard: Historia de las ideas politicas, Madrid, 1975. 
és pas un dret natural. Els demòcrates, diu, intenten la demostració contrària en voler provar aqueli dret com a dret natural, però ens cal reconèixer que totes dues demostracions són, en rigor, discutibles, car parteixen d'un postulat extracientífic, no d'un axioma científicament evident: «En un cas de moral o de dret variarà el valor d'una demostració segons el valor del postulat sobre el qual descansa» (p. 2). Així, l'evidència o valor de veritat dels postulats avaluatius és variable. Un cop fet aquest oportú aclariment ens parla de tres modalitats històriques del dret monàrquic o de la desigualtat: per dret «diví», per dret «humà» (variant deI dret pattimonial) i per dret "civil», quan hom estableix, en aquest últim cas, la font de la mo natquia en els mateixos ciutadans. Les dues primeres formes són per a ell teòricament irtecusables; només la tercera és conceptualment problemàtica. Perquè: "Quan en una època determinada de la històtia es conceptua evident aquest postulat, els defensots de la monarquia es troben en greus dificultats $[\ldots]$. En un moment així els escriptors monàrquics deixen en segon pla la qüestió del dret de la monarquia i tracten de demostrar la seva utilitat per als ciutadans» (p. 2). Ara, doncs, subratllada la insolubilitat teòrica de la fonamentació «civil» de Maurtas, com es comprovatà, no es pot parlar ja del $d r e t$ de la monarquia en la seva concepció contemporània, sinó de la seva utilitat.

Arribat aquest punt Crexells ens posa, com a exemple d'aquells que defensen el monarca per la seva «utilitat», Hobbes i els monarquistes contemporanis. I afegeix: «Êsset rei, aleshores, no és -o no és primàriament- exercitar un dret, sinó ésser l'instrument del qual es val la collectivitat per a aconseguir la seva ptòpia felicitat» (p. 2). Hem arribat, així, fins a Hobbes, $i$ tot seguit ens diu: «... en un moment com el d'ara tots els aspectes repugnants de la monarquia es converteixen en gràcies» (p. 3), afirmació que recusa implícitament el cinisme de Hobbes, i no tant de Maurras, que és apologètic, en presentar-nos, a la fi, com un bé allò que ell mateix teconeix com un mal. Les argumentacions en defensa de la monarquia com un dret (el dret diví dels teòcrates, el dret patrimonial dels positivistes) constitueixen per a Crexells la «teoria ingènua de la monarquia», mentre que les advocacions al monarca pels esperats efectes de la seva gestió de govern representen la «teoria cínica de la monarquia»: "Quan una teoria política manté una posició defectuosa des del punt de vista de la justícia, a consciència que és defectuosa en dret, perquè és avantatjosa en fet, crec que està ben qualificada quan se'n diu una teoria cínica» (p. 3). Interrompem, però, l'article de Crexells per passar a estudiar breument els dos exemples de «teoria cínica» que ens posa l'autor: Maurras i Hobbes. 
Hobbes i el monarquistne modern

\section{MAURRAS, O L'AGONIA DEL MONARQUISME MODERN}

El pensament monarquista de Charles Maurras està recollit principalment, gairebé codificat, en la seva obra L'enquête sur la Monarcbie, que agafa una nombrosa sèrie d'entrevistes amb comentari, realitzades pel ma. teix Maurras a destacats royalistes francesos entre els anys 1905 i $1910{ }^{8}$ A tots ells (aux bons français, segons Maurtas) se'ls formula una única i mateixa pregunta: «Oui ou non, l'institution d'une monarcbie traditionelle, berédittaire, antiparlamentaire et décentralisée est-elle de salut public?» La pregunta és la vera síntesi de tots els principis que bastiran les pàgines del seu llibre sobre la monarquia.

El punt de partida de Maurras és una doble af́rmació: el «desordre» republicà, que pretén presentar-nos-el com una constatació de fet, i l'«ordre» monàrquic, que gosa mostrar-nos-el com una necessitat. Així, comença parlant-nos de la «perf́́dia» i feblesa intimes del sistema republicà» (p. XV), el qual és incapaç de resoldre «les affaires de la France». La democràcia, nogensmenys, és «llei del nombre» i està establerta "contra-natura», perquè en ésser plebiscitària exclou la qualitat, condició de I'«organització» que regeix la naturalesa. A més, està fonamentada - lluny de fer-ho sobre l'«interès general comú», sobre el qual s'estableix, segons ell, el lloable «règim sindicalista»-_.9 en la "voltuntat i opinió de l'individu», quan els interessos particulars «són els destructors de l'intetès general» i porten indefectiblement a la «tirania de les faccions» (p. 141): «La démocratie c'est le mal. La démocratie c'est la mort» (p. 119). Contínuament proclama que la causa de tot aquest desori tesideix en la revolució del 1789, en els seus defensors entre els romàntics liberals (es baralla especialment amb Hugo i Michelet) i en una curiosa amalgama d'individus sediciosos que no ha de parar fins a veure enfonsada la Pàtria: els protestants, els jueus, els francmaçons i els estrangers. Amb tot, ens ha de confessar: «... c'est l'affaire Dreyfus qui m'a

7. Livrairie Nationale, París, 1910. Altrament, per a una introducció prou clarificadora a aquest voluminós i espès text, tan difícil de trobat avui, cf. el capítol dedicat a ell en J. J. Chevallier: Los grandes textos politicos, Madrid, 1974. L'editorial Livrairie Nationale estava especialitzada en l'edicio de textos similars al de Maurras; evidentment, es trobava relacionada amb els grups d'Action Française i de la «Gazette de Frances.

8. No cal dir que Monseigneur Le Duc d'Orléans, pretendent a la Corona de França en l'exili, tingué l'honor de ser, significativament, el primer entrevistat. Seguiren personatges prou expressius per ells mateixos com Barrès, Lemaitre, Amouretti...

9. El sindicalisme antipartidista i nacionalista s'estengué per França i Itàlia des dels anys deu fins al decenni dels vint. Cal recordar que el seu màxim teòric fou el francès Georges Sorel, tan admirat per aquell que hauria de ser un dia falangista, el català Eugeni d'Ors. 
fait sentir clairment pourquoi la République était impuissante a résoudre une affaire d'Etats (p. 252).

Per a Maurras, vehement defensor de la filosofia positivista i del primat cientificista, i amb una veneració tan extrema com simptomàtica envers Comte, la democràcia ha esdevingut finalment una «religió». Tot això parla per si mateix, i és així que, decididament: «La irresponsabilitat, l'anonimat, la incúria, Ia inestabilitat del poder parlamentari republicà, fan indispensable una enèrgica intervenció personal» (p. 313). Sols la monarquia pot realitzar la «paix publique»: «Sense detenir els moviments de la vida francesa, els pot distribuir segons el seu ordre, l'únic que concilia en lloc d'oposar, l'únic que utilitza en lloc de malgastar' (p. XLII). És prou conegut el nacionalisme doctrinari i integrista de Maurras, que associa el patriotisme a la monarquia contrarevolucionària. D'aquesta manera, «... pràcticament, com teòricament, si hom vol ésser nacionalista, no hi ha més que el partit del Nacionalisme integral, és a dir, la Monarquia» (p. 304).10

El projecte de monarquia proposat per Maurras pretén presentar-nos un règim reial necessari i provat. Ell en diu «científic», i parla ben clar quan sentencia: «La Monarcbie, comme la Science, est réaliste. Elle no se paye point de mots» (p. 117). Reitera encara aquest apuntat nominalisme quan més endavant de l'obra afirma ben explícitament: «El nou règim serà sintètic [...] utilitzarà tot el vocabulati polític del nostre temps, cada terme usat segons una accepció definida» (p. 323). Al capdavall, el poder teial encarna una «... très baute autorité scientifique» (p. 183). Maurras ens diu fins $i$ tot que la república ha de morir pel laïcisme i pel cientificisme que ella mateixa defensa, gràcies als quals, segons el conspirador de l'Action, s'han preparat les bases del monarquisme. Ben sovint, "'autor de L'Enquête es proclama «realista» $\mathrm{i}$ «empiric», referint-se a la institució monàrquica com una solució de la «intelligència» i del «sentit pràctic», contra la confusió despertada per l'«economia i la moral», oposades al sentit correcte que per a Maurtas hauria de tenir la política. El monarquisme és, per tant, una «política realista», basada en els fets i de caràcter pragmàtic, que cerca adés el «salut public», adés la permanència de la realitat viva de la «Nation». Maurras no apella Déu ni la Terra, ni els sentiments ni la raó, sinó senzillament el «sentit comú», altrament anomenat «intelligència»: «... és impossible de fer l'igualitarisme adequat a la naturalesa i al sentit comú» (p. 373). No es tracta amb això de ressuscitar el sentiment o l'ideal

10. Malgrat que Maurras declara La Tour du Pin «mon maître direct», cal trobar els antecedents $i$ les bases del seu pensament polític en tots els pensadors contrarevolacionaris $\mathrm{i}$ tradicionalistes francesos del $\mathrm{xrx}$, principalment De Maistre, Bonald, Comte, Le Play, Fustel de Coulanges, Renan, Taine i Bartès. Maurras subratila preferentment, però, el seu deute amb el positivisme i el nacionalisme. 
monàrquic, sinó de restaurar el fet mateix de la monarquia amb motio de la seva utilitat, tenint ben present que en l'horitzó es troba, per a l'autor del Hibre, la fidelitat a la Nació francesa. El fi, si es vol, és la Nació/ «salut public», mentre que el mitjà avinent és la Monarquia/«intelligence»: «El meu objecte, la Monarquia francesa, preexistia, perquè ella ha fet França, que ens ha fet a tots» (p. XVIII). La Monarquia fa, doncs, la Nació. Segons Maurras, l'Estat post-revolucionari és, en contraposició a la societat coronada de l'Ancien Régime, el malaguanyat trionf dels «Drets de l'ho. me» sobre els «Drets de l'Estat», del «Sistema» contra la «Política», de la «Metafísica» sobre la "Ciència» $i$, en definitiva, en un familiar antagonisme per als teòrics de la dreta, de la «Raó» sobre la «Intelligència». Unes dicotomies, així, pseudo-positivistes, propiciadores d'arguments pro-autorita" ristes, pretextats sobre una presumpta desigualtat natural entre els homes, comuns en tota l'obra de Maurras i d'altres pensadors socials llatins del post-positivisme, tan característics pel seu tarannà irracionalista." Però no sols trobem en el fons del discurs maurrasià el peculiat biologisme que imprimeix a les seves expressions un notable to determinista sinó que, paradoxalment, $i$ sense introduit en la seva exposició elements voluntaristes - escatològics, adopta sovint els postulats del determinisme bistòtic. Així, la royauté, el monarquisme, vénen donats per la mateixa «evolució social», i no en virtut de transformacions econòmiques o d'idearis socials. És l'«évolution sociale» qui dicta la progressiva compatibilitat dels «dos pobles parlamentaris i liberals per excellència», Bèlgica i el Regne Unit, ${ }^{12}$ amb el tègim monàrquic, i marca, contràriament, la progressiva separació entre les masses revolucionàries i el règim republicà, cono s'observa, diu, a França i a Itàlia ( $«$... la misère logique des républicains contribue à la monarchie», p. 324).

Quins són, però, els elements que han de fer possible la restitució del fet monàzquic? Quin és el procediment per a acomplir el projecte monarquista? Amb un conegut mot de guerra, Maurras demana "Politique d'abord!». Certament, els seus planteigs són d'un deliberat signe politicista. No hi valen consideracions alienes a la política pragmàtica que dicta el «realisme» dels nacionalistes. Maurras posa la política per damunt de tot en els mitjans per a retrobar la Corona. Però no qualsevol política, sinó la d'aquest «realisme». Així: «Le réalisme politique oppose a cette Liberté

11. Ortega y Gasset, Maeztu, d’Ors, Pareto, Gentile, Barrès, Péguy, ctc,, teoritzadors de l'Estat de les èlites, en el sí d'un moviment ideològico-cultural de dreta davant l'avenç del socialisme.

12. En parlar d'aquests països, aprofita per celebrar el sentit municipalista i cooperatiu - vol dir corporatith - de Ilur socialisme, a despit dels moviments socialistes republicans $i$ estatistes -jacobins - dels altres països europeus. 
révolutionnaire, qui détruit l'Êtat et le citoyen, la concepition des libertés traditionnelles du pays» (p. XXXIII). Hom pot apreciar fàcilment l'estil corporativista i prerevolucionari d'aquesta declaració, en dir no a la llibertat. indivisible, horitzó de la voluntat revolucionària, per reivindicació de les llibertats definides, locals i corporatives. Maurras reclama, doncs, el dret a l'associació professional, al reagrupament confessional, a la familia, a l'autonomia municipal, a la província, a la fundació de centres privats d'ensenyament i beneficència, a l'autonomia sindical... La seva obsessiva idea de la décentralisation posarà, per tant, la família en lloc de l'individu, la província en lloc de l'Estat jacobí, l'associació gremial en lloc de la competició parlamentària, els costums en lloc de les institucions $i$, en darrer terme, les libertats en comptes de la Llibertat, la jerarquia en Iloc de la igualtat. El procediment «royaliste» és aquest doble front de descentralització geogràfica i social. «Révolution contre Révolution», ens dirà.

Pet a dur a terme la política monarquista «... calen obrers especials». Millor: «... un patriciat ben constituït.» «Un grup petit és suficient. Si és actiu, intelligent $i$ decidit, pot determinar $i$ aconseguir almenys el consentiment de l'Armada francesa, on els elements monarquistes són abundosos...» (p. 182). Ėite, jerarquia i "compétence»: l'eficàcia, la competència, un altre leitmotiv maurrasià. Ara bé, una condició s'ha de donar per tal que la minoria d'experts realitzi la descentralització amb la restauracio de la Monarquia: «... tenen necessitat de l'ordre públic per tal d'acomplir-se amb utilitat» (p. XLIV). Finalment, Maurras Iliga tots els caps esmentats d'ordre, jerarquia i eficàcia quan subratlla: «Una democràcia no s'organitza, perquè la idea d'organització, en qualsevol cas, exclou la idea d'igualtat en qualsevol grau: organitzat és diferenciar $i$, en consequiència, establir graus i jerarquies» (p. 117).

Maurras enyora Louis XIV, i pensa en el Duc d'Orléans per a succeirlo en la més alta magistratura. França és «poignarde», «le peuple est poignard»: el poble francès necessita un puny. «El poble també espera $i$ reclama una autoritat enèrgica, perquè s'exerceixi en favor del bé públic» (p. 367). Cal adreçar els interessos particulars, ens diu, als interessos generals; i és precisament le Prince l'òrgan d'aquest interès general: un òrgan «vivant et puissant» que realitzi el principi de mon-arquia enfront del de poliarquia. El Príncep precedeix l'ordre; la Monarquia preexisteix a la Nació.

«Per tal que França visqui i prosperi, cal, de tota necessitat, un poder central fort, independent, essencialment nacional. Però aquestes tres condicions de nacionalització, independència i força no s'obtenen més que per la institució d'una monarquia hereditària i tradicional, que suprimeixi o repri- 
meixi el parlamentarisme; que, altrament (és el seu luxe), tealitzi un tipus de continuïtat perfecte; que, en definitiva, permeti i faciliti el "gran avantatge" de la descentralitzaciós (p. 501).

Maurras, així, posa un ènfasi especial en el fet que ta monarquia és necessària per «evolució social» i perquè, endemés, França, el poble francès, són poignards; però recalca sobretot que ha de ser hereditària, car només la successió dinàstica permet la continuitat que necessita la nació per a sobreviure. La dinastia és, pet a l'escriptor francès, «la génératrice de nôtre nationalité». La corona és gairebé imposada per selecció naatural: el biologisme que la justifica -el positivisine-- és el distintiu essencial d'aquest monarquisme. Quant a la legitimació del sobirà, no recorre ni a la font providencial ni al principi del pacte: el monarca és l'únic capaç de garantir el «bé comú» -o l'《interès general»-, i prou. Per al testabliment de la cotona cal que «hom es desprengui de la seva part de sobirania, - que hom abdiqui la seva reialesa particular». La Restauració abolità el tègim de «guerra civil» inherent al parlamentarisme. I afegeix, contundent: "L'bereuse impopularité du parlamentarisme permettra au Prince d'y procéder avec une extrême facilitề (p. 320). L'hereditat dinàstica és consubstancial amb la nació, i aquesta amb la «salvació pública». Per a fer el nationalisme intégral cal, doncs, teeixir en el royalisme. L'èxit de les «repúbliques aristocràtiques», ens diu Maurras, s'explica perquè, a diferència de les repúbliques democràtiques, aquelles (Atenes, Roma, Venècia) han sabut aplicar en primer lloc la llei política de l'hereditat, i en segon lloc potquè en elles s'ha acomplert la nacionalització del poder.

\section{HOBBES, EN ELS ORIGENS DEL MONARQUISME MODERN}

El pensament filosòfico-polític de Thomas Hobbes es troba exposat principalment en el seu tractat de teoria política titulat Leviathan, ${ }^{13} \mathrm{i}$ subtitulat, expressivament, The matter, form and power of a commonwealth, ecclesiastical and civil. Fou editat per primera vegada l'any 1651 , mentre Cromwell era al poder.

Per a la nostra anàlisí del monarquisme ens basem especialment en la

13. Tradució castellana đ'A. Escohotado: Leviatán, Editora Nacional, Madrid, 1979. Pet a l'estudi del pensament polític hobbesià pot consultar-se amb profit, entre una selecta però no nombrosa bibliografia sobre Hobbes, el text de l'especialista francès R. Polin: Politique et pbilosopbie cbez Hobbes, Paris, 1953. 
segona part del llibre en qüuestió, tota ella dedicada a l'Estat o Commonwealth.

En el llibre de Hobbes s'introdueix per primera vegada en la història de la teoria política la teferència a la Raó com a garant universal del discurs polític. Hobbes, però, no contraposa els conceptes de Natura i Raó: aquesta és al servei de la primera, es manifesta per ella i no es desvia de les seves lleis. No pot ésser veritable alì̀ que contradiu la Џlei natural. Hobbes, certament, segueix el mètode científic a l'hora d'estudiar la realitat. ${ }^{14} \mathrm{EI}$ seu antiessencialisme l'acostà al convencionalisme científic; àdhuc s'integra en la tendència ètica voluntarisła, característica entre els autors anglosaxons, bé que subsisteix en totes les seves exposicions una concepció organicista de premisses naturalistes. La seva Commonwealtb, per exemple, assumeix un cert hilemorfisme aristotèlic, en ésser presentada al lector com a composta d'un «cos» —els súbdits—-i d'una «ànima» --el sobirà. Així mateix, Hobbes descriu aquest Estat mitjançant la metàfora del cos humà: els ministres del sobirà són els «òrgans», els jutges la «veu», les riqueses la «sang», etc. Inclusivament ens parlarà de la «generació», de la «nutrición, de la «procreació i de les «malaities» de la república. Tampoc no fa concessions a la metafísica ni a la moral, en Ilur sentit més continental. Ell no parla, per exemple, ni de virtut ni de justícia, sinó de pau i de benestar. És un pragmàtic convençut, encara que un individualista. És prou conegut, altrament, que se sol posar a Hobbes entre els predecessors de l'utilitarisme filosòfic. «La llei natural i la lei civil es contenen l'una a l'altra» (p. 349): el proposit que anima Hobbes sembia voler civilitzar el natural i natura litzar el civil. Amb una singular correcció de les teories del dret natural, estableix la seva ptòpia noció de Dret Natural, fonamentat en un principi de conservació i descobert per la Raó, com a sobreposat al concepte d'Estat de Naturalesa, regit, aquest, pel principi d'anarquia. Aquest Dret Natural que vertebra tota la seva teoria política conté dues lieis essencials: preservar-nos d'una mort violenta i garantir-nos el màxim possible de felicitat individual. Per tal d'assegurar-ho, Hobbes ens proposa el Pacte interindividual amb la transferència dels drets personals a un sobirà elegit entre tots. Però això ve després.

La Raó, així, descobreix les tleis naturals de conservació i gaudi de la vida, i estableix també la llei civil per assegurar-les contra l'estat de naturalesa. Aquest és el caos, la guerra civil: l'bomo bomini lupus. El Poder Civil, doncs, realitza ha Llei Natural. Malgrat que el basament teòric de

14. El cientificisme de Hobbes pot descompondre's en una doble influència: an. glesa, pel seu nominalisme, $\mathrm{i}$ continental, pel característic atomisme $\mathrm{i}$ deductivisme que acompanyà tots els seus escrits. L'influïren, principalment, Galileu i Gassendi, 
Hobbes és naturalista, el primat l'ocupa la llei civil: «... el dret natural, aixó és, la lilibertat natural de l'home, pot ésser reduït o limitat per la llei civil» (p. 350). Amb el Leviatban es dóna, així, la superació teòtica de l'Estat Natural per l'Estat Polític, la civitas o Estat sensu stricto. Com es constitueix $i$ es garanteix, però, el poder civil, clau de volta del sistema polític hobbesià? Es constitueix gràcies a l'interès i a la voluntat individual de tots; és el resultat d'una decisió, no d'un designi transcendent o d'una fatalitat. La decisió es produeix per una mera necessitat d'autoprotecció davant dels previsibles excessos dels altres: «EI fi de la república és la seguretat dels particulars» (p. 263). Hobbes distingeix, així, entre l'establiment del poder per força i la constitució del poder per pacte. La primera forma, també anomenada per ell «patriarcal» $\mathrm{i}$ «despòtica», fa possible la «República per adquisició», mentre que la segona manifestació sưposa ja un estadi superior: la «República per institució». El poder, aquí, és pròpiament republicà perquè s'estableix per pacte i cessió de tots i cadascú. Sì el poder delegat republicà resideix en una assemblea estem davant d'una De. mocràcia, si recau en un grup es tracta d'una Aristocràcia, i si es limita a un home sol patlem d'una Monarquia. Hobbes prefereix aquesta vatiant, i l'exalta. Veurem per què.

El poder sobirà tepresentatiu es correspon amb l'alienació del dret que, per naturalesa, tenen els homes de protegir-se. Les tres classes de Commonwealth ${ }^{15}$ preveuen respectivament tres classes de govern. El millor govern és, per a Hobbes, aquell que resulta de fer residir el poder en una sola persona. La Monarquia té més avantatges, segons cl pensador anglès, que la resta de modalitats d'entendre la república. I ho justifica, tot argu. mentant que el Monarca: a) Assumeix «la seva pròpia persona natural»; b) rep conseil de qui vol $i$ amb el secret que vol; c) les seves resolucions no tenen la pressió del «nombre» («... a les assemblees, juntament amb la inconstància de la naturalesa, brolla la inconstància provinent del nombre», p. 281); ${ }^{16} d$ ) a diferència, també, de l'assemblea, el monarca no pot estar en desacord amb ell mateix, per la qual cosa no pot ésser causa de guerra civil; $e$ ) és inevitable que el monarca tingui la possibilitat d'afavorir uns sobre uns altres, però això passa també a les assemblees, on l'espectacle és tnés dramàtic encara; if) si la seva defunció origina querelles, no és pas per culpa d'ell, sinó per causa de l’ambició dels súbdits. Malgrat que Hob.

15. Hobbes no parla pròpiament de tres classes de poder, sinó d'«aptitud», i ens dirà: «La diferència entre aquestes tres classes de tepública no consisteix en la diferència de poder, sinó en la diferència de conveniència, d'aptitud per a produir la pau i la seguretat del poble, finalitat per la qual foren institurdes» (p. 280).

16. Les pàgines $280-290$ de j'edicio castellana, veritable apoteosi del monarca, contenen un bon nombre de similars declaracions antiparlamentàries. 
bes reivindica la naturalesa representativa del monarca, procedent tan sols del pacte interindividual, i deixa ben entès que la decisió del sobirà és la decisió dels súbdits, és partidari que el monarca tingui dret a nomenar successor i, així, que els monarques successors no siguin en realitat electius, sinó hereditaris. L'autor de Leviatban no pot ésser més expressiut quan puntualitza:

«Però si no hi ha ningú que pugui donar la sobirania després del traspàs de l'elegit en primer lloc, aquest té poder i està obligat per llei natural a proveir, mitjançant l'establiment del seu successor, allò necessari pet a evitar una recaiguda d'aquells que if havien confiat el govern en el miserable estat de guerra civil» (p. 285).

El sobirà, tanmateix, ha de ser l'únic legislador, l'únic que mana complir la llei $i$, a més, aquell que posseeix la qualitat d'ésser jutge sobirà que constitueix els altres jutges. La jurisprudència, segons Hobbes, és falsa, perquè està basada en la llei dels escriptors (autoritat moral), mentre que la justícia del monarca és llei de la república (autoritat civil). El poder del sobirà és, đoncs, indivisible, i per això mateix no està obligat per cap voluntat ni disposició aliena. El poder del monarca és illimitat: «... ol rei el poder del qual és limitat no és superior a aquell o aquells que tenen poder per a limitar-lo» (p. 285). El sobirà no està sotmès a cap lỉei civil: «... el poder del sobirà ha de ser absolut en totes les repúbliques» (p. 298). Aquest poder sobirà ha de ser, altrament, «tan gran com els homes hagin pogut imaginar», i tecalca, en recerca de fonament, "tant a partir de la raó com de l'Escriptura» (p. 298). Els drets del sobirà són justiffcats per la raó i no tenen més liei que la llei de Déu. Si es vol, l'única limitació humana del sobirà ve de la seva pròpia raó, car no seria raonable que el sobirà no busqués l'interès del sel poble, que és ai capdavall el seu propi interès... És evident que Hobbes és ben diferent de Bossuet, petò tro és, en canvi, massa lluny de Bodin. L'obra política de Hobbes és la primera racionalització de l'absolutisme tradicional, tot i que ara és la raó qui ens fa abandonat el dèspota...

«L'única manera d'erigir un poder comú capaç de defensar-nos [...] és conferint tot el poder $\mathrm{i}$ tota la força a un home o a una assemblea, que pugui reduir totes les voluntats, per pluralitat de veus, a una voluntat» (p. 266). La frase és prou concisa, si hom llegeix només «assemblea», per a fonamentar, certament, la doctrina tradicional del liberalisme, però es fa força ambivalent en afegir-hi la possibilitat de concentrar tot el poder en un sol home: s'està fakcant l'absolutisme. «El poder sobirà ha de ser absolut en totes les repúbliques». Si a més a més tenim en compte la preferència 
explícita de Hobbes pel monarca i tenim presents expressions tan singulars com «... la condició humana mai no pot deixar de tenir una incomoditat o altra» (p. 277), o el seu cèlebre bomo bomini..., tindrem el terreny adobat per a qualsevol de les futures teoritzacions justificadores de l'absolutisme polític. I tot a partir de la raó i de l'Escriptura. Així mateix, contra tot aquell qui s'oposi al poder absolut del sobirà, argumentarà Hobbes amb dramàtica ironia que «haurà de sotmetre's ell mateix al poder que pot limitar-lo [al poder del sobirà], és a dir, a un de més gran» (p. 298). Reconeix cínicament que "l'objecció principal és la de la pràctica», però de seguida s'apressa a declarar que una argumentació basada sobre la pràctica és «invà+ lida» per als homes «... que no han sondejat fins al fons ni mesurat amb exacta raó la naturalesa de les repúbliques» (p. 299). Com l'aritmètica, dirà Hobbes, la república es basa en unes regles; en unes «regles», està clar, «... que els pobres no han tingut oci per a descobtir, com no han tingut interès o curiositat els ociosos» (p. 299). Ningú no se salva del menyspreu. La comprensió de l'absolutisme del monarca, com es veu, està reservada només als bons coneixedors d'aquelles «regles»: als que coneixen amb «exacta raó». Som cada vegada més a prop de l'elitisme dels «obrers de la política» - i de gairebé tot el pensament- de Maurras.

La manca de poder absolut és «la pitjor de les malalties» que poden afectar Ia Commonwealth. La segueixen, per otdre d'importància, les «doctrines sedicioses», sotmetre el sobirà a les Ileis civils i dividit el poder d'aquest (pp. 395-399). Allò, però, que més intolerable és per a Hobbes es troba en les llibertats polítiques més primordials. L'autor ens subratlla que $« \ldots$ on regnen els homes no pot permetre's una diversitat d'opinions» (p. 403). Es prou evident, en bona lògica hobbesiana, que on no hi ha diversitat de poders o, millor, poder diversificat, no hi pot haver diversitat d'opinions. La representativitat del primer sobirà estatuit pel pacte —però no la dels seus successors- justifica per a Hobbes dos arguments essencials en la seva concepció política de l'absolutisme: a) La monatquia hereditària és representativa; $\mathrm{i} b$ ) el pluralisme atempta contra aquesta representativitat.

Com podria donar-se consistència al règim parlamentari amb uns principis tan autocràtics? En realitat, però, el mèrit de Hobbes és haver-se atrevit a enunciar allò que la seva classe feia. El seu liberalisme és tot el que dóna de si el liberalisme. I Hobbes ens ho explicita tan lúcidament com rigorosament; formalitza en la teoria la concepció pràctica del liberalisme entès com a legalització filosòfico-política del capitalisme ascendent, en la seva fase més pletament metcantilista. En certa manera, i valgui la digressió, ¿no constitueixen les repúbliques de la Comissió Trilateral, les del capitalisme monopolista actual, un disseny molt semblant al de la «re- 
presentació» política amb gran reforçament de l'executiu, tal com Hobbes ens ha deixat minuciosament apuntat en el seu Leviathan?

En Hobbes es tracta de fonamentat la libertat econòmica de l'individu - per exemple, el burgès- sobre aquell Estat que és capaç de garantir la seguretat política que necessiten les seves activitats, que no són, precisament, les dels «pobres» o les dels «ociosos»... Alhora, aquells que pretenen «disputar contra el poder sobirà» són «com els petits cucs que els metges anomenen ascàrides» (p. 406). Hobbes ens ho repeteix: en abdicar cadascú el seu dret absolut en favor del sobità absolut es renuncia també a la llibertat de jutjar el bé i el mal. Els súbdits no tenen Ilibertat i se'ls ha d'ensenyar a conformar-se, perquè són "com paper en blanc». L'exercici de la llibertat després del pacte és un atemptat, ens dirà, contra la conservació de la vida. Com tots els bons autoritaristes, Hobbes oposa llibertat i seguretat. «La por i la llibertat són compatibles» (p. 300).

El projecte de Hobbes ja no és utopia, com en Campanella o en More, perquè és la racionalització (cosa que no s'atreveix a fer un contemporani seu, Bossuet, armb el tègim de Lluís XIV) de l'Estat, de la Commonwealth cromwelliana; com, més endavant, un altre anglosaxó, Hegel, tacionalitza l'Estat prussià. Es tracta, certament, d'un projecte racional, bé que prou fundat sobte bases que excedeixen la raó de la democràcia per a ésser, a la $\mathrm{fi}$, un règim raonable. En rigor, l'Estat hobbesià no es fonamenta en la táo que el teòric diu usar per a descobrir-nos-el. El fonament discursiu de l'Estat de Hobbes va a parar a la religió revelada. El poder civil està basat, segons aquest autor, en les lleis de Déu, $i$ hom pot entendre que el Leviatban és la laiicització de la Santa Aliança bíblica, o, si es vol, la seculatització dels Manaments de la Llei de Déu. ${ }^{17}$ És ara el Monarca omnipotent qui, en successió de Moisès - que consumà el Pacte de Déu amb el Poble-, ha d'administrar el «Regne de Déu per Naturalesa», com anomena Hobbes la seva Commonwealth.

Llavors el Pacte hobbesià, segons aquesta lectura, és més la «civilitzaciós del Pacte búblic que l'actualització del Contracte del dret romà. Per un doble motiu: per la naturalització (prescriptivitat de la Llei Natural) i, altrament, per la secularització (estipulació de la Llei Civil) de la Llei Divina. Hobbes oposa aquestes dues lleis, la Natural i la Civil -domini de la Seguretat que dóna la Raó i l'Escriptura alhora-, a la per ell anomenada Llei de la Naturalesa, o domini de la Llibertat.

17. Eis «manaments» primers que el monarca ha d'ensenyar als súbdits es corresponen, i Hobbes ho diu explícitament, amb els Manaments de Ja Llei de Déu. Així: hom no cercarà cap altre sobirà (primer manament), hom no disputarà el poder del sobirà (segon), etc. I afegirà: «... els súbdits deuen als sobirans simple obediència en totes les coses on no sigui incompatible amb les lieis de Déu» (p. 425). 
Certament, l'autor de Leviathan no apella a la religió històrica o positiva dels medievals, per exemple (malgrat que tampoc no es remet a la religió natural o teista), sinó que realizza l'original operació de posar, en Ia teoria, la religió en dependència del poder civil, i de donar-li un estatut civil. Una religió civil en la qual no importatà tant la fe o la Veritat com la Voluntat o l'obediència. Hobbes és un Bodin tenyit de Maquiavel.

\section{LA CRITICA DE HOBBES A PARTIR DE CREXELLS}

Continuem ara amb l'article de Joan Crexells en el punt on l'haviem Jeixat. El reprenem en aquell passatge que el filòsof català dedica a resumir els arguments amb els quals Hobbes, en el seu Leviathan (segona part, cap. XIX), pretén provar la superior utilitat del monarca sobre l'assemblea: «Aquests arguments tan actuals no són, com algú podrà creure, un resum de certes teories de l'Action Française, sinó un fragment de Hobbes» (p. 6). De la mateixa manera, i un cop embastat el parallelisme Maurras-Hobbes, procedeix -després de citar els inconvenients ínfims que Hobbes posa a la Monatquia en comparació amb la Democtàcia- a esmentar les diferències - «algunes diferències»-- entre ambdós autors. En primer Iloc, segons Crexells, Hobbes és diferent dels "hobbesistes moderns» (Maurras i els monarquistes com ell) en la mesura que «hi ha l'avantatge, en Hobbes, de La precisió i de l'esperit sistemàtic propis del flòsof professional, i de l'estil ferm i segur com el d'un escolàstic i alhora ple de passiós (p. 7). A més:

«En els moderns, el que la monatquia serveix és una cosa sanguejant de vida: la nació. Un problema de filosofia política es planteja en els segles XVIY i XVIrr com un problema de matemàtiques; la seva relació amb la vida sembla llunyana; el mateix problema, en el segke XIX o ara, té tota la gravetat d'una intervenció quirúrgica; la relació amb la vida és immediata. Per a Hobbes cal salvar la Commonwealth, evitar que tornem a la lluita de tots contra tots... coses llunyanes!; per a Maurras, cal salvar aquesta cosa vital i immediata que és la pàtria» (p. 7).

I, encara, un altre punt interessant, conclou Crexells, és que «Hobbes sosté que Monarquia, Aristoctàcia i Democràcia tenen teòricament els mateixos drets i són sobiranes igualment» (p. 8); i en relació a la seva infuència possible sobre Maurras i a la mateixa licitud d'aquest, escriurà: 
«Situat actualment a França, amb una democtàcia sobirana que protegeix efectivament els seurs súbdits, extingits tots els drets de tot monatca, perquè cap delis monarques francesos és vivent, una conseqüència del sistema de Hobbes seria que cal mantenit la forma democràtica existent» (p. 8).

Hom no pot acusar, doncs, Crexells d'una lectura parcial del Leviathan. Això no obstant, $i$ després d'haver reconegut els continguts liberalistes de l'obra de Hobbes, afegeix, per contra, que «Hobbes ens dóna, doncs, un resum magnific de tots els arguments que trobem en els monàrquics moderns» (p. 8). Perquè, recordem-ho, Hobbes reconeix de dret la legitimitat de l'assemblea, però menysprea la democtàcia per una inferioritat de fet amb la monarquia. Crexells ha copsat perfectament el fons de l'ambivalència de la teoria hobbesiana, la duplicitat de la lectura del Leviathan.

També hem de reconèixer, tal com ens ajuda a valorar Crexells mateix, l'aportació de Hobbes a la història de la filosofia política. No hem de desconsiderar, amb tot, el vocabulari utilitzat per l'autor angtès, bàsicament, encara, el llenguatge de la teoria contemporània, ${ }^{16}$ donat el caràcter o connotació política dels seus termes. En opinió meva, cal fer sobresortir els següents aspectes de valor en Hobbes autor polític: a) El rebuig de tot allò que transcendeix la voluntat humana en la constitució civil (ens parla d'«interès», i no de «destíi», per exemple); b) la formalització raonada de la necessitat d'establir un poder sobirà (d'alguna manera, en explicar-nos la naturalesa civil de l'Estat prepara ja les posteriors teoritzacions del liberalisme sobre el sistema de govern. Locke, per exemple, és impensable sense Hobbes); i c) l'adhesió estrictament racional, ni sentimental ni escatològica, del súbdit al seu sobirà, per haver-lo instituit.

D'altra banda, hom pod̉itia començar a xifrat les dificultats que presenta la teoria política de Hobbes pel salt efectuat des de l'explicació de l'origen del poder sobirà (amb els seus plantejaments, Hobbes supera els autors del "postulat monàrquic», com Bodin o Bossuet) fins al fet de detallar els efectes profitosos de la seva utilitat (com féu Maquiavel), sense valorar, per sobre del seu origen $i$ de la seva utilitat, la validesa o la racionalitat del seu exercici (aspecte en el qual insistiren altres teòrics del pacte contemporanis de Hobbes: Althusius, Grotius...). És per això que podem veure Hobbes més a la vora dels llunyans Maquiavel o Maturras que dels propers Althusius o Locke, en un sentit cronològic. Més concretament, la coincidència de Maurras (malgré lui, probablement, car no la subscriví lite-

18. Hobbes ens parla, per exemple, de «pacte», de «representació», d'«elecció», de «república institucional», de «súbdits», de «poder sobirà», de «liei civil»... 
ralment) amb Hobbes es pot veure fàcilment en el fet que ambdós autors sustenten el mateix argument legitimador del monatca absolut: només en la monarquia l'interès del governant coincideix amb l'interès del governat. Tots dos teòrics tenen especialment en comú una concepció naturalista (organicista en Hobbes, darwinista en Maurras) a l'hora de descriure la societat civil, i una confessió pragmatista a l'hora de prescriure les regles polítiques que l'hauran de constituir. Malgrat aquest projecte compartit de «política natural» encaminada a satisfer l'«interès públic», ens trobem davant d'algunes remarcables diferències de concepttració: el model hobbesià està construït amb el mètode axiomàtic de la maternàtica, mentre que el prototip metodològic maurrasià és el de la biologia. En el primer autor, el monatca és descober per la tá́ i reconegut per les escriptures bíbliques; en Maurras, en canvi, el tei és imposat pel sentit comú i reconegut per la mateixa evolució natural. Hi ha, però, una motivació gairebé idèntica per a posar el monarca. Aixt, Hobbes demana que imposi la Llei que ha d'alliberar-nos de la guerra civil, i Maurras postula que imposi l'Ordte que ens ha de deslliurar de la revolució.

Els dos autors coincideixen, alhora, en el fet que (lievat del primer monarca, en Hobbes) el sobirà no ha de ser electe, sinó hereditari i absolut. Així mateix, també tots dos parteixen d'un pressupòsit irracional, d'estricta estimació personal: l'«Homo homini lupus» en Hobbes i «La France est poignarde» en Maurras. Adhuc en els dos escriptors constatem la secularització del poder absolut, impartit tradicionalment per designi diví: en el filòsof anglès se secularitza en nom dels interessos dels homes, i en l'escriptor francès es fa en nom de la nació. Existeix, però, una gran diferència entre ambdós projectes absolutistes, i és que l'absolutisme de Maurras no té el caràcter plebiscitari i consensual que exigeix la dictadura proposada/consagrada per Hobbes sinó que, lluny de fer-la residir en un origen electiu o en una formulació teoctàtica, fa basar la legitimitat del sobirà en la mera dinastia familiat, el tradicional llinatge, la qual cosa converteix el seu ideari en un programa molt més a la vora de les aristocratitzants teories de les èlites que d'un monarquisme polític estricte. El seu absolutisme és positivista, o aspira a ser-ho.

Fet i fet, no oblidem que Hobbes és flòsof i Maurras només un publicista que, malgrat la contundència de la seva intervenció en la vida pública, la consistència de la seva obra no sobrepassa la d'un panflet desesperat. 


\section{EPILEG}

Ara fa dos anys es complia el tercer centenari de la mort de Thomas Hobbes. En la línia de fonamentació teòrica del modern Estat burgès, des. prés de Maquiavel i Bodin, aquell flòs of de la política arribà a viure noranta-un anys, volgudament incontaminat per la pràctica política $i$, poruc com era, havent demostrat que sabé aplicar a la seva pròpia vida els dos grans postulats de la seva saviesa política: evitar a tort i a dret el perill d'una mort violenta i aprofitar ai màxim els propis recursos.

Si ens hi fixem, aquests dos principis es corresponen precisament amb els dos objectius fonamentals que per a Hobbes ha d'acomplir l'Estat. El Leviatban disposa per a tot profit dels seus súbdits ni més ni menys que la pau i la llibertat. Però, és clar, en la teoria hobbesiana s'han de llegir aquests dos magnes vocables amb la justa clau que utilitzà l'autor per a manejar-los: en termes de «seguretat». El Leviathan, l'Estat salvaguardador, justifica el seu caràcter total només amb el compliment de fer efectiva la promesa seguretat dels individus que comprèn. Aquest Estat atomitzador $\mathrm{i}$ athora totalitzant que Hobbes dissenyà es basteix tant sobre les conviccions més íntimes - la suspicàcia invariable envers l'altre-com sobre l'esquema més abstracte: l'Estat com a únic recurs de la raó per a assegutar la vida. Individualisme i abstracció, doncs, posats al servei de tota una ideologia de la seguretat.

El preu d'aquest gran pas en la història de la teoria política, aquell haver sabut passar de la fictio (l'entelèquia medieval del Contracte) a la ratio (la determinació de la Sobirania política), ha de suposar per a uns un cost massa alt, per a d'altres un cost ben grat, però siqui com sigui un preu evident per a tots, estatistes o antiestatistes. Perquè amb Hobbes es consolida allò que des de Maquiavel s'anava insinuant; a saber, la justifi. cació de l'Estat ja no com una utopia, sinó com una idea tacional operativa. Hobbes, tot establint el seu Leviathan a manera d'artifici, li imposa de bell nou el distintiu de la raó: l'últim gran filòsof de l'Estat, el primer gran tractadista ensems. D'ara endavant, per a l'Estat ja no hi ha d'haver ni societat ni grups socials, sinó individus. Ell és la "persona collectiva» que representa tots $\mathrm{i}$ cadascun d'ells. I prou. També a partir d'ara la societat no podrà ser sinó com a Estat, i no serà vàlida cap norma jurídica que d'ell no provingui. L'Estat és àrbitre, però també interventor; assisteix, però també agredeix. La reila marcada en la història pei Leviathan encara fa via. El projecte d'un Estat màximament organitzat $i$ interventor, és a dir, total (posi's el sufx que es vulgui a aquest mot), es realitza semblantment avui a l'Alemanya de l'Oest $i$ a la de l'Est, als Estats protectors dels Drets Humans i als de la Gran Pàtria Socialista. 
Per això, en conclusió, em sembla útil la crítica de Crexells a Hobbes, en ocasió del feixisme maurrasià. En el monarquisme modern veu Crexelis una perillongació del complex ideològico-institucional concebut per l'autor anglès. Petò no cal limitar-se a Crexells, evidentment, per destruir la vigèncía actual de les fonts doctrinals de l'Estat Absolut de Dret, en tota la seva diversa fenomenologia present. Altrament, cap teòric clàssic del marxisme no ha vist en el Leviatban hobbesià aquest «punt de partida» que veuen alguns marxistes moderns per a arribar a la societat socialista, des de socialdemòcrates com Araquistain mateix fins a eurocomunistes com Bobbio. En l'actual corrent marxista advers al «mite» de la desaparició de l'Estat, d'arrel post-gramsciana, i de signe clarament corporativista («expansió de la democràcia política»), el recurs a Hobbes ha esdevingut un valor paradigmàtic.

Sigui com sigui, i per acabar parlant de Hobbes mateix, jo també he fet, com Crexells, una lectura del Leviatban com un breviari del totalitatisme, i espero haver-ho sabut explicar. 